(C) The Authors 2020. Published by Cambridge University Press on behalf of The Nutrition Society.

\title{
Corrigendum
}

\section{An Evaluation of Food Provision to Jockeys in the Weigh Room at Irish Racecourses- CORRIGENDUM}

\author{
Esme Ward, Ruth Drennan, Adrian McGoldrick, Clare Corish and Gillian O’ Loughlin \\ Proceedings of the Nutrition Society, First View article \\ doi: 10.1017/S0029665120005078, Published online by Cambridge University Press, 10 June 2020
}

The above mentioned abstract was submitted to Cambridge University Press with incorrect author information. Esme Ward and Ruth Drennan were given as "Esme / Ruth Ward / Drennan"

This has since been corrected.

\section{Reference}

Drennan, E, McGoldrick, A, Corish, C \& O’ Loughlin, G (2020) An Evaluation of Food Provision to Jockeys in the Weigh Room at Irish Racecourses. Proceedings of the Nutrition Society 79(OCE2), E558. doi:10.1017/S0029665120005078 